\title{
LATIN IN UNIVERSITY ENTRANCE REQUIREMENTS
}

$\mathrm{T}$ HE controversy about compulsory Latin for entrance to Oxford and Cambridge flares up sporadically, like the plague, but it does look as though the recent outbreak may be the last. True, Oxford has reversed its decision to make German and Russian alternatives to Latin; but when the committee at present looking into the qualifications for university entrance reports, it seems likely that some means will be recommended whereby Latin can be avoided.

It is difficult to see what benefit the average boy (or girl) who wants to specialize in science can derive from Latin at Ordinary level in the General Certificate of Education. He will not be able to read the simplest texts with any ease, even if he wanted to, and the feeling among many scientists that Latin is a waste of time makes it very unlikely that he will. His attitude to Latin, which is often crammed in a few months and as quickly forgotten, is one of resigned hostility.

"Without Latin the specialists will become even more specialized" is a favourite argument of the anti-abolitionists, yet very few people wish to abolish it unconditionally. At Oxford the suggestion was that Russian and German should be alternatives, and a scientist with French and German is no more a specialist than one with French and Latin. Besides, there is far more chance that a modern language will be kept up, since even the least materialistically minded can see its usefulness. More and more people go abroad every year, especially school children and university students, and later on the professional scientist will want to read papers in foreign languages. Few are published in Latin.

Three main arguments are advanced by those who wish to see Latin retained besides the one mentioned above.

First, they say that it is the key to the understanding of Western culture. Quite apart from the fact that Latin at Ordinary level is not even a key to the understanding of Latin, in order to 'understand' Western culture one has to know a good deal about it, and, as is so frequently pointed out, most scientists do not--though many are more knowledgeable than is often allowed. Latin is, no doubt, an immense asset to the scholar with a wide knowledge of the literature, philosophy, art and history of Europe and America, but to the scientist it is rather like studying the quantum theory without knowing what radiation and algebra are; or, to take a nonscientific simile, to study the sources of Shakespeare's plays without having read "Hamlet". With an educational system which imposes specialization at the age of fifteen we cannot afford the time for intellectual luxuries. It is the stuff of Western culture that should be studied, not Latin grammar.

Secondly, Latin is said to be a unique training for the mind. This argument is difficult to refute, since it is so vague and is so seldom elaborated. It is significant that it is usually advanced by people whose mental training was largely based on Latin. Furthermore, mathematicians can make a similar claim for mathematics with equal justice. Part of the uniqueness of Latin is said to lie in its being a highly inflected, and so a very precise, language; but so are German and Russian.

Thirdly, Latin is said to improve one's English. Maybe it does, but it is an extraordinarily roundabout way of doing so, and one for which the scientist simply does not have the time.

In fact, Latin tends to defeat the very objects it is meant to attain. It becomes associated with other non-scientific subjects and produces an anti-cultural refiex-Latin is a waste of time, therefore French, history and English are a waste of time. It also takes up valuable hours in school which might be devoted to arts subjects likely to interest the potential scientist. It is not suggested that the time spent on Latin should be given over to more science. A debate held recently in the University of London on the motion "That the Education of our Future Rulers should be primarily in the Sciences rather than the Humanities", where scarcely a speaker from an audience containing many scientists supported the motion, shows how much basic agreement there is that education ought not to become too specialized. In view of this, it is a pity that such an issue should have been made out of the relatively unimportant Latin question.

It is high time that some effort was made towards improving the genoral, as opposed to the specialized, standards for university entrance. If the Latin dispute does nothing else, it focuses attention on this need. Scientists entering for State scholarships already have to take a general paper in English, but it is a special paper for scientists, and so in a sense it condones the existence of Sir Charles Snow's two cultures, instead of tending to re-unite them. If only the universities would demand from everyone three subjects at Advanced level, one a science and one an arts subject, there would be no need to quibble about trivialities like Ordinary level Latin. Quite apart from the wider knowledge this would bring, scientists and arts men would be working together right up to the time they left school, and this is surely essential if they are not to separate into two groups. It has been suggested that as a consequence there would be a slight lowering of standards in the entrance scholarships, and that the colleges would not accept this. If so, it would be a great pity, but it would be a very small price to pay. Besides, it is illogical to complain about specialization and to object to measures which combat it.

Anyone who wants to see compulsory Latin retained for scientists should sit back and ask himself two questions : What am I trying to achieve? What is the best way of going about it? It is very peculiar reasoning that produces Latin at Ordinary level as an essential part of the final answer. The worthy cause of a wider education is being discredited. 